\title{
BMJ Open From hospice to hospital: short-term follow-up study of hospice patient outcomes in a US acute care hospital surveillance system
}

\author{
Elizabeth Barnett Pathak, ${ }^{1}$ Sarah Wieten, ${ }^{1,2}$ Benjamin Djulbegovic ${ }^{1}$
}

To cite: Pathak EB, Wieten S, Djulbegovic B. From hospice to hospital: short-term follow-up study of hospice patient outcomes in a US acute care hospital surveillance system. BMJ Open 2014;4:e005196. doi:10.1136/bmjopen-2014005196

- Prepublication history for this paper is available online. To view these files please visit the journal online (http://dx.doi.org/10.1136/ bmjopen-2014-005196)

Received 5 March 2014 Revised 1 July 2014 Accepted 4 July 2014

CrossMark

\footnotetext{
${ }^{1}$ Division of Evidence-Based Medicine, Morsani College of Medicine, University of South Florida, Tampa, Florida, USA 2Department of Philosophy, University of South Florida, Tampa, Florida, USA

Correspondence to Dr Elizabeth Barnett Pathak; epathak@health.usf.edu
}

\section{ABSTRACT}

Objectives: In the USA, there is little systematic evidence about the real-world trajectories of patient medical care after hospice enrolment. The objective of this study was to analyse predictors of the length of stay for hospice patients who were admitted to hospital in a retrospective analysis of the mandatorily reported hospital discharge data.

Setting: All acute-care hospitals in Florida during 1 January 2010 to 30 June 2012.

Participants: All patients with source of admission coded as 'hospice' ( $\mathrm{n}=2674)$.

Primary outcome measures: The length of stay and discharge status: (1) died in hospital; (2) discharged back to hospice; (3) discharged to another healthcare facility; and (4) discharged home.

Results: Patients were elderly (median age $=81$ ) with a high burden of disease. Almost half died (46\%), while the majority of survivors were discharged to hospice ( $80 \%$ of survivors, $44 \%$ of total). A minority went to a healthcare facility $(5.6 \%)$ or to home $(5.2 \%)$. Only $9.2 \%$ received any procedure. Respiratory services were received by $29.4 \%$ and $16.8 \%$ were admitted to the intensive care unit. The median length of stay was 1 day for those who died. In an adjusted survival model, discharge to a healthcare facility resulted in a $74 \%$ longer hospital stay compared with discharge to hospice (event time ratio (ETR) $=1.74,95 \% \mathrm{Cl} 1.54$ to $1.97 p<0.0001$ ), with $61 \%$ longer hospital stays among patients discharged home (ETR=1.61, 95\% Cl 1.39 to $1.86 p<0.0001$ ). Total financial charges for all patients exceeded $\$ 25$ million; $10 \%$ of patients who appeared to exit hospice incurred $32 \%$ of the charges.

Conclusions: Our results raise significant questions about the ethics and pragmatics of end-of-life medical care, and the intentions and scope of hospices in the USA. Future studies should incorporate prospective linkage of subjective patient-centred data and objective healthcare encounter data.

\section{INTRODUCTION}

Hospice care is a specialised approach to end-of-life medical care that emphasises

\section{Strengths and limitations of this study}

- One of the largest studies until now to explore acute-care hospitalisations of hospice patients, a neglected aspect of the dying patient's experience.

- Recent, unbiased and comprehensive surveillance data from the fourth largest state in the USA (Florida) were analysed.

- Detailed analyses of morbidities, in-hospital procedures, length of hospital stay and financial charges were included for four distinct patient groups: patients who died, those who returned to hospice, those who were transferred and those who went home without hospice care.

- Limitations included probable under-reporting of hospice as source of admission; inability to distinguish which morbidity was the terminal illness and lack of information about patient/caregiver preferences for end-of-life care and place of death.

quality of life, pain management and symptom alleviation for terminally ill patients. In the USA, hospice care is usually provided in the patient's home or in a nonhospital facility, and it typically excludes curative-intent medical or surgical interventions. The goal of hospice care is not to prolong life or postpone dying, but rather to achieve a 'good death.' Generally, the preferred length of enrolment in hospice is about 6 months before death, but some guidelines point to a recommended stay of 1 year. ${ }^{1}$ As a stipulation for receiving hospice benefits from most US insurance payers, the patient relinquishes access to curative interventions, although the patient can opt out of hospice at any time to regain this access. The idealised patient trajectory that is evoked by hospice advocates is that after patients and families come to terms with the terminal nature of the illness, patients will live out the remainder of their days peacefully at home 
or in a hospice facility with minimal medical intervention prior to death.

However, there is very little systematic evidence about the real-world trajectories of patient medical care after hospice enrolment in the USA. Instead, previous hospice studies have focused on whether the use of hospice or advanced directives decrease the cost of end-of-life care ${ }^{2-4}$ or increase the quality of life before death. ${ }^{5}{ }^{6}$ These studies of cost and quality of life have generally assumed the idealised trajectory of hospice care, without considering the possible impact of hospitalisations. Previous reports on the phenomenon of post-hospice hospital admissions have been small cohorts ${ }^{7}$ or single-centre studies ${ }^{89}$ and have found that hospitalisation of hospice patients can not only be costly and largely preventable but also that positive patient outcomes for interventions on non-terminal conditions (like hip fractures) might explain some hospice patient hospital admissions.

In this study, one of the largest so far of hospice-to-hospital patients, we analysed very recent data from a statewide hospital surveillance system for all inpatients whose source of admission was coded as 'hospice.' We report patient demographics and clinical characteristics; hospitalisation procedures, duration and outcomes; and detailed financial charges. Finally, we modelled predictors of length of hospital stay for the majority of these terminally ill hospice patients who survived to discharge. Given that one of the core goals of hospice programmes in the USA is to avoid unnecessary and futile medical care at the end of life, we presumed that a long hospital stay would constitute a negative and unwanted outcome for most hospice patients.

\section{METHODS}

Our study population consisted of all patients at Florida acute care hospitals whose source of admission was coded 'hospice' in the state hospital discharge surveillance system. Other common sources of admission include emergency department, hospital transfer, patient home and skilled nursing facility. In 2010, the reporting requirements were modified and a new code to identify hospice patients was added. In this study, we aggregated 2.5 years of data (1 January 2010 to 30 June 2012) for analysis.

Hospitals in Florida are mandated by state law to submit detailed discharge records of all patients. Consequently, these data can be considered a surveillance system with $100 \%$ coverage. Data items available include patient demographics, payer, length of stay, admission diagnosis, principal diagnosis, up to 30 secondary diagnoses, principal and secondary procedure codes and detailed financial charge data.

We analysed data for four distinct groups based on discharge status/destination. The groups were (1) patients who died prior to discharge; (2) patients who were discharged back to hospice (either home hospice care or a hospice facility); (3) patients who were discharged to a healthcare facility (including transfer to another acutecare hospital, skilled nursing facility, intermediate-care, long-term care or rehabilitation facility); and (4) patients who were discharged home (either with or without home health assistance, but without hospice). For each of our four study groups, we calculated prevalence rates for common admission diagnoses, any-mention diagnoses and procedures. Specifically, 'any-mention diagnosis' was based on any mention of a condition in any of 32 diagnosis fields (including admission diagnosis, principal diagnosis and secondary diagnosis fields). Multiple ICD-9-CM codes were combined into categories in some cases. Patients with a diagnosis of heart failure included those with chronic, acute exacerbation or both. A diagnosis of psychosis included those who were suffering from serious behavioural effects of Alzheimer's disease. While the principal diagnosis code is intended to capture the most serious medical condition suffered by the patient (eg, lung cancer), the admission diagnosis code is intended to identify why the patient was admitted as an inpatient to the hospital (eg, acute respiratory failure). Consequently, admission diagnosis codes may include diseases, symptoms, signs or 'V-codes', which are ICD-9-CM codes that describe social circumstances, medical history or other pertinent patient information not captured by traditional organ system-based disease codes. For example, the code V66.7 indicates an episode of palliative healthcare.

Payer categories included Medicare (federal government health insurance for the elderly), Medicaid (federal/state health insurance for low-income persons), Tricare (federal health insurance for military personnel and their dependants), commercial (all non-government health insurance plans including employer-provided plans) and other (including self-pay/underinsured, charity, worker's compensation and other miscellaneous small programmes).

Procedures (up to 31 per patient) were identified by ICD-9-CM procedure codes. Procedures could include major therapeutic interventions (eg, surgery), minor therapeutic interventions (eg, breathing treatment), diagnostic procedures (eg, MRI, CT scan and colonoscopy) and minor routine procedures (eg, insertion of catheters).

Given that hospital financial coverage is constrained by some payers for hospice patients based on length of stay, we examined predictors of duration of hospital stay using a Weibull accelerated failure (event) time survival model. ${ }^{10}$ The Weibull model permits calculation of 'event time ratios (ETRs)', which are a more appropriate measure of effect for this study than HRs. This is because our primary interest is not in whether or not an event occurs (all patients eventually leave the hospital), but in whether there are factors that accelerate or delay time to event (ie, days until discharge). ETRs provide a proportional measure of direct impact on time to event (eg, an ETR of $1.25=\mathrm{a} 25 \%$ increase in the length of hospital stay). We first fit a model with a large number of 
potential predictors. For the final model, we retained all covariates with an initial $\mathrm{p}$ value $\leq 0.15$.

In addition, some payers will cover occasional hospitalisations of limited duration (eg, $\leq 5$ days) for hospice patients, for the purposes of respite care or medical attention to a condition which is not the terminal illness. ${ }^{1}{ }^{11}$ Therefore, we used a multivariate logistic regression model to examine the dichotomous outcome of long ( $\geq 6$ days) vs short ( $\leq 5$ days) hospital stays among survivors.

Finally, we examined detailed financial charge data available for each patient as a proxy for costs. We evaluated which charge centres (eg, pharmacy and intensive care) were contributing to total costs both overall and stratified by patient discharge status. We report the percentage of patients with a non- $\$ 0$ charge in a given charge centre, and the median and 99th centile dollar values (calculated based only on the distribution of non-\$0 values).

This study was classified as non-human subjects research by the USF Institutional Review Board because it relied solely on de-identified secondary database analyses.

\section{RESULTS}

\section{Patient discharge status}

There were a total of 2764 patients whose source of admission was reported as 'hospice' during the period 1 January 2010 to 30 June 2012 at acute-care general hospitals in Florida. The discharge status of these patients is shown in figure 1. Almost half of these patients died prior to discharge (46\%), while the majority of survivors were discharged back into a hospice programme $(80 \%$ of survivors, $44 \%$ of total). Patients discharged home $(5.2 \%)$ included those who were scheduled to receive home healthcare.

\section{Patient characteristics, diagnoses and length of stay}

Characteristics of patients by discharge status are shown in table 1 . The overall median age was 81 years (range 0-106 years); however, non-trivial minorities of each

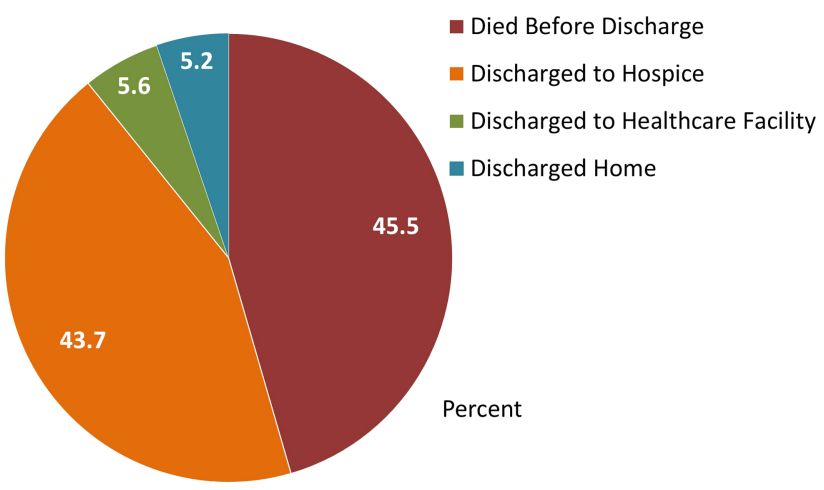

Figure 1 Discharge outcomes for patients admitted to a hospital from hospice, Florida 2010-2012 ( $n=2674)$. group were aged $<65$ years $(12.8-45.7 \%)$, and $5 \%$ of the patients discharged home were markedly younger than the other three groups (median age $=67$ ). The majority of patients were White non-Hispanic $(70.8 \%)$, followed by Hispanic (19.9\%). The majority of patients had Tricare health insurance $(51.5 \%)$, followed by other $(25.4 \%)$, private/commercial insurance $(16.8 \%)$ and Medicare or Medicaid (6.3\%).

As expected, these terminally ill patients suffered a high burden of serious illness. The most prevalent diagnoses (based on any mention) are listed in table 1 . Some of these conditions were chronic diseases (eg, hypertensive disease, any heart disease, cancer and chronic obstructive pulmonary disease (COPD)), while others probably reflected acute conditions that may have precipitated hospital admission (eg, respiratory failure, acute renal failure, stroke, pneumonia/influenza and sepsis).

The median length of stay for all patients was 2 days, with a range of 0-99 days. While only $10.7 \%$ of hospice patients had a stay of 6 or more days, a longer length of stay was much more prevalent among patients discharged to a healthcare facility $(32.9 \%)$ or home $(21.7 \%)$. In contrast, patients who died were most likely to have a length of stay of zero days $(22.8 \%)$, meaning that those patients died on the same day that they were admitted to the hospital.

\section{Admission diagnoses}

The top admission diagnoses for patients in our study population are depicted in figure 2. For a terminally ill patient suffering from multiple chronic and acute conditions, the choice of a single admission diagnosis may be somewhat arbitrary. In aggregate, however, these codes provide a window of insight into the diverse challenges present in medical management of the dying patient. Top admission diagnoses among patients who were discharged to a healthcare facility included palliative care (16.1\%), cancer $(6 \%)$, psychosis $(4.7 \%)$, altered mental status $(4 \%)$ and pneumonia/influenza (3.4\%). Among patients who were discharged home, top diagnoses included cancer $(8.7 \%)$, respiratory symptoms $(7.3 \%)$, drug/alcohol dependence $(6.5 \%)$ and psychosis $(6.5 \%)$.

\section{Medical and surgical procedures}

Overall, the use of procedures was very limited in this population of terminally ill hospice patients, with only 9.2\% overall receiving any procedure (table 2). Among patients who died, 95.2\% received no procedure. Invasive mechanical ventilation was provided in $1 \%$ of these patients, and non-invasive mechanical ventilation in $0.8 \%$. At least one procedure was received by $6.8 \%$ of patients who were discharged to hospice. In this group, the two most common principal procedures were paracentesis $(1 \%)$ and transfusion of packed cells $(0.9 \%)$.

Procedure use was more common among patients who did not return to hospice $(33.6 \%$ for those who were discharged to a healthcare facility and $41.3 \%$ for those who 
Table 1 Characteristics* of patients admitted from hospice by final discharge status, Florida 2010-2012

\begin{tabular}{|c|c|c|c|c|c|}
\hline & $\begin{array}{l}\text { Died before } \\
\text { discharge } \\
(n=1217)\end{array}$ & $\begin{array}{l}\text { Discharged to } \\
\text { hospice }(n=1170)\end{array}$ & $\begin{array}{l}\text { Discharged to a } \\
\text { healthcare facility } \\
(n=149)\end{array}$ & $\begin{array}{l}\text { Discharged } \\
\text { home }(n=138)\end{array}$ & $\begin{array}{l}\text { Total } \\
(n=2764)\end{array}$ \\
\hline Median age & 80 & 81 & 84 & 67 & 81 \\
\hline \multicolumn{6}{|l|}{ Age, years (\%) } \\
\hline$\leq 64$ & 16.1 & 15.2 & 12.8 & 45.7 & 17.1 \\
\hline $65-74$ & 18.1 & 14.9 & 16.1 & 18.8 & 16.6 \\
\hline $75-84$ & 29.5 & 30.3 & 26.2 & 21.7 & 29.2 \\
\hline $85-94$ & 31.1 & 33.7 & 38.3 & 9.4 & 31.5 \\
\hline $95+$ & 5.3 & 6.0 & 6.7 & 4.4 & 5.6 \\
\hline \multicolumn{6}{|l|}{ Gender (\%) } \\
\hline Male & 49.1 & 47.5 & 38.9 & 40.6 & 47.4 \\
\hline Female & 50.9 & 52.5 & 61.1 & 59.4 & 52.6 \\
\hline \multicolumn{6}{|l|}{ Race/ethnicity (\%) } \\
\hline White & 73.7 & 69.6 & 72.5 & 52.9 & 70.8 \\
\hline Hispanic & 17.0 & 22.5 & 16.8 & 26.8 & 19.9 \\
\hline Black & 6.9 & 6.7 & 9.4 & 15.2 & 7.4 \\
\hline Other & 2.4 & 1.3 & 1.3 & 5.1 & 2.0 \\
\hline \multicolumn{6}{|l|}{ Payer (\%) } \\
\hline Medicare/Medicaid & 1.3 & 4.2 & 35.6 & 37.0 & 6.3 \\
\hline Private insurance & 14.7 & 19.2 & 6.0 & 26.1 & 16.8 \\
\hline Tricare/Federal & 57.7 & 49.8 & 40.3 & 23.2 & 51.5 \\
\hline Other & 26.3 & 26.8 & 18.1 & 13.8 & 25.4 \\
\hline \multicolumn{6}{|c|}{12 Most prevalent diagnosest } \\
\hline Hypertensive disease & 37.6 & 46.4 & 62.4 & 50.7 & 43.5 \\
\hline $\begin{array}{l}\text { Non-ischaemic heart } \\
\text { disease }\end{array}$ & 31.1 & 32.1 & 38.3 & 18.8 & 31.3 \\
\hline Cancer & 28.1 & 36.6 & 23.5 & 19.6 & 31.1 \\
\hline Respiratory failure & 37.9 & 18.8 & 17.5 & 10.1 & 27.0 \\
\hline $\begin{array}{l}\text { Ischaemic heart } \\
\text { disease }\end{array}$ & 25.1 & 25.0 & 33.6 & 21.0 & 25.4 \\
\hline $\begin{array}{l}\text { Chronic obstructive } \\
\text { pulmonary disease }\end{array}$ & 23.9 & 25.9 & 27.5 & 21.0 & 24.8 \\
\hline Heart failure & 25.4 & 22.3 & 21.5 & 19.6 & 23.5 \\
\hline Psychosis & 15.9 & 28.4 & 43.6 & 28.4 & 23.5 \\
\hline Acute renal failure & 16.7 & 13.4 & 18.1 & 10.9 & 15.0 \\
\hline Stroke & 15.6 & 11.8 & 13.4 & 8.7 & 13.5 \\
\hline $\begin{array}{l}\text { Pneumonia or } \\
\text { influenza }\end{array}$ & 14.1 & 14.2 & 12.1 & 2.2 & 13.4 \\
\hline Sepsis & 13.6 & 8.8 & 9.4 & 3.6 & 10.8 \\
\hline $\begin{array}{l}\text { Median length of stay } \\
\text { (days) }\end{array}$ & 1 & 2 & 3 & 3 & 2 \\
\hline $\begin{array}{l}\text { Per cent with stay } \\
>5 \text { days }\end{array}$ & 9.7 & 7.6 & 32.9 & 21.7 & 10.7 \\
\hline
\end{tabular}

${ }^{*}$ All per cents are column per cents.

†Based on a mention in any of the 32 diagnosis fields. Each patient could have multiple diagnoses.

were discharged home). Top procedures for hospice patients discharged to a healthcare facility were percutaneous endoscopic gastrostomy (PEG) $(3.4 \%)$, venous catheterisation $(2 \%)$ and transfusion of packed cells $(2 \%)$. For patients discharged home, drug detoxification was the top procedure $(5.1 \%)$, followed by PEG $(2.2 \%)$.

\section{Predictors of the hospital length of stay}

We found several significant predictors of length of hospital stay in an accelerated event time survival analysis of all hospice patients who survived to hospital discharge $(\mathrm{n}=1457)$, as shown in table 3. ETRs significantly $<1.00$ indicate predictors that shortened the length of stay (ie, accelerated time to discharge), while ETRs significantly $>1.00$ indicate factors that delayed hospital discharge. We first fit a model with a large number of potential predictors. For the final model, we retained all covariates with an initial $\mathrm{p}$ value $\leq 0.15$. Potential predictors which were NOT included in the final model were: sex, COPD, ischaemic heart disease, HIV, hypertensive disease, any fracture, respiratory failure, drug/alcohol dependence, sepsis, acute renal failure, end-stage renal disease and 

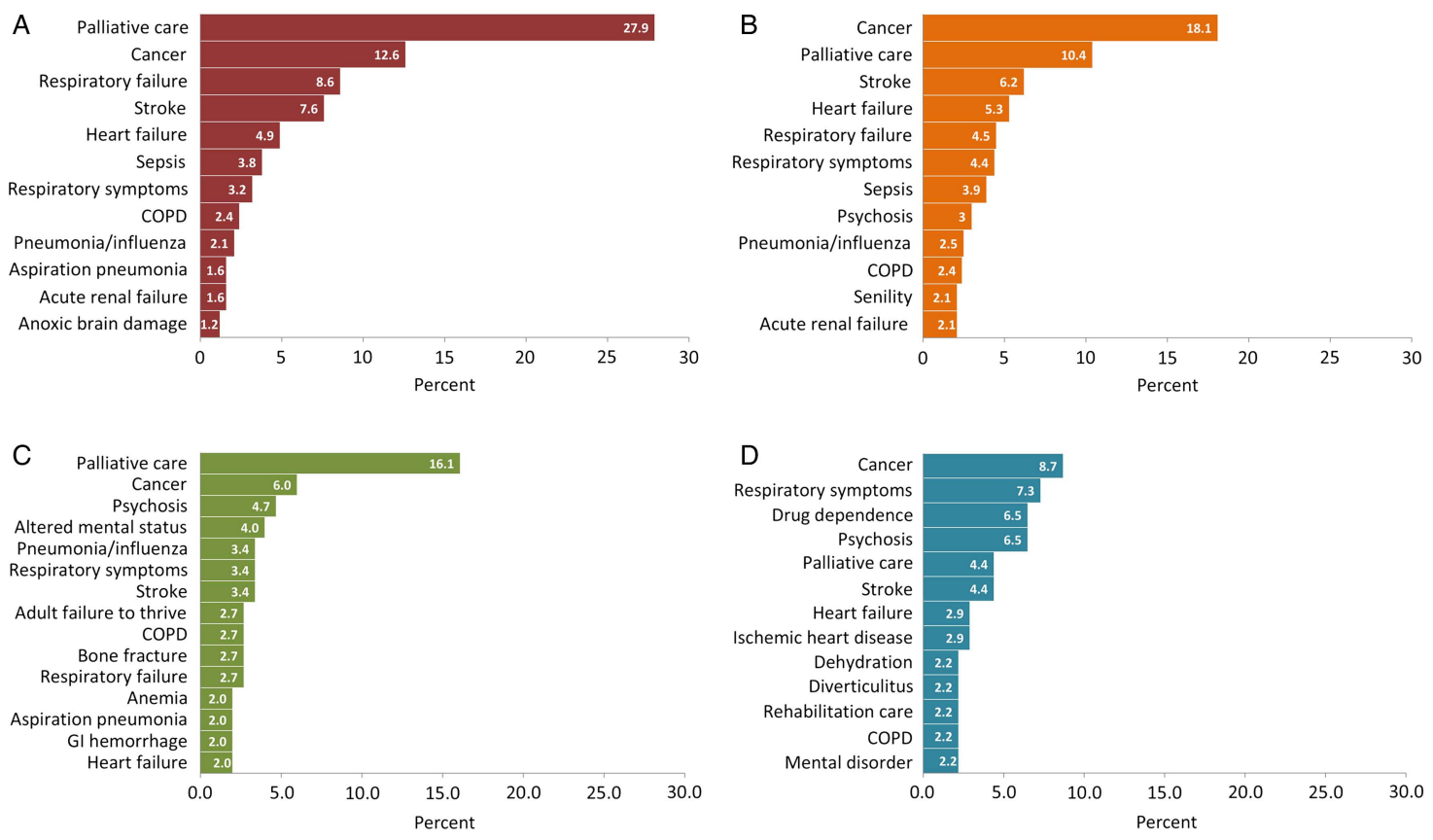

Figure 2 (A) Top admission diagnoses for hospice patients who died prior to hospital discharge $(n=1217)$. (B) Top admission diagnoses for hospice patients who were discharged back to hospice $(n=1170)$. (C) Top admission diagnoses for hospice patients who were discharged to a healthcare facility $(n=149)$. (D) Top admission diagnoses for hospice patients who were discharged home without hospice care $(n=138)$. COPD, chronic obstructive pulmonary disease; Gl, gastrointestinal.

senility. The only patient characteristic that shortened hospital stay was older age. For example, compared with those $\leq 64$ years of age, patients aged 85-94 years had hospital stays that were $35 \%$ shorter (ETR $0.65,95 \%$ CI 0.58 to $0.74, \mathrm{p}<0.0001)$. In contrast, several factors lengthened hospital stays, including Medicare/Medicaid (74\% longer stays than those with private insurance), discharge home $(61 \%$ longer stays than those who returned to hospice) or to another healthcare facility ( $74 \%$ longer stays than those who returned to hospice) and Hispanic ethnicity $(12 \%$ longer stays than non-Hispanic Whites). Clinical diagnoses that increased the length of stay included medical complications/infections (43\% longer stays than those without these diagnoses), stroke (29\% longer stays), heart failure (18\% longer stays) and psychosis (13\% longer stays). A

Table 2 Most prevalent principal procedures* for hospice patients admitted to a hospital, Florida 2010-2012

\begin{tabular}{|c|c|c|c|c|c|}
\hline & $\begin{array}{l}\text { Died before } \\
\text { discharge } \\
(n=1217)\end{array}$ & $\begin{array}{l}\text { Discharged to } \\
\text { hospice }(n=1170)\end{array}$ & $\begin{array}{l}\text { Discharged to a } \\
\text { healthcare facility } \\
(n=149)\end{array}$ & $\begin{array}{l}\text { Discharged } \\
\text { home }(n=138)\end{array}$ & $\begin{array}{l}\text { Total } \\
(n=2764)\end{array}$ \\
\hline Per cent with no procedure & 95.2 & 93.2 & 66.4 & 58.7 & 91.8 \\
\hline $\begin{array}{l}\text { Mechanical ventilation for } \\
<96 \mathrm{~h}\end{array}$ & $\mathrm{n}=12$ & $n=8$ & $n=1$ & $n=1$ & $n=22$ \\
\hline Venous catheterisation & 6 & 8 & 3 & 1 & 18 \\
\hline Blood transfusion & 4 & 11 & 3 & 0 & 18 \\
\hline Non-invasive ventilation & 10 & 5 & 2 & 0 & 17 \\
\hline Paracentesis & 1 & 12 & 1 & 0 & 14 \\
\hline Enteral feeding & 9 & 2 & 0 & 0 & 11 \\
\hline $\begin{array}{l}\text { Percutaneous endoscopic } \\
\text { gastrostomy }\end{array}$ & 1 & 1 & 5 & 3 & 10 \\
\hline $\begin{array}{l}\text { Insertion of an endotracheal } \\
\text { tube }\end{array}$ & 4 & 2 & 2 & 0 & 8 \\
\hline Drug detoxification & 0 & 0 & 0 & 7 & 7 \\
\hline Haemodialysis & 1 & 3 & 1 & 0 & 5 \\
\hline Radiation therapy & 0 & 3 & 1 & 1 & 5 \\
\hline Interruption of vena cava & 0 & 2 & 1 & 1 & 4 \\
\hline Mechanical ventilation $\geq 96 \mathrm{~h}$ & 1 & 1 & 2 & 0 & 4 \\
\hline
\end{tabular}


Table 3 Predictors of the length of hospital stay among hospice patients who survived to discharge $(n=1457)$ : multivariate accelerated event time survival analysis results

\begin{tabular}{|c|c|}
\hline Patient predictors & $\begin{array}{l}\text { Event time ratio }(95 \% \mathrm{Cl}) \\
\text { ( } \mathrm{p} \text { value) }\end{array}$ \\
\hline \multicolumn{2}{|l|}{ Discharge destination } \\
\hline Hospice & 1.00 (referent) \\
\hline Healthcare facility & $1.74(1.54$ to 1.97$)(<0.0001)$ \\
\hline Home & $1.61(1.39$ to 1.86$)(<0.0001)$ \\
\hline \multicolumn{2}{|l|}{ Age, years } \\
\hline$\leq 64$ & 1.00 (referent) \\
\hline $65-74$ & $0.73(0.64$ to 0.84$)(<0.0001)$ \\
\hline $75-84$ & $0.69(0.61$ to 0.78$)(<0.0001)$ \\
\hline 85-94 & $0.65(0.58$ to 0.74$)(<0.0001)$ \\
\hline $95+$ & $0.72(0.61$ to 0.86$)(0.0003)$ \\
\hline \multicolumn{2}{|l|}{ Race/ethnicity } \\
\hline White & 1.00 (referent) \\
\hline Hispanic & $1.12(1.03$ to 1.22$)(0.01)$ \\
\hline Black & $1.06(0.92$ to 1.22$)(0.44)$ \\
\hline Other & $1.82(1.37$ to 2.42$)(<0.0001)$ \\
\hline \multicolumn{2}{|l|}{ Payer } \\
\hline Private insurance & 1.00 (referent) \\
\hline Medicare/Medicaid & $1.74(1.50$ to 2.02$)(<0.0001)$ \\
\hline Tricare/Federal & 1.21 (1.09 to 1.34$)(0.0002)$ \\
\hline Other & $0.93(0.84$ to 1.04$)(0.21)$ \\
\hline \multicolumn{2}{|c|}{ Clinical diagnoses (present vs absent) } \\
\hline $\begin{array}{l}\text { Medical complications/ } \\
\text { infections }\end{array}$ & $1.43(1.18$ to 1.73$)(0.0002)$ \\
\hline Stroke & $1.29(1.15$ to 1.44$)(<0.0001)$ \\
\hline Heart failure & $1.18(1.07$ to 1.30$)(0.001)$ \\
\hline Psychosis & $1.13(1.04$ to 1.23$)(0.04)$ \\
\hline Pneumonia/influenza & $1.11(1.00$ to 1.24$)(0.06)$ \\
\hline Other heart disease* & $0.92(0.85$ to 1.01$)(0.08)$ \\
\hline Cancer & $1.07(0.98$ to 1.17$)(0.11)$ \\
\hline
\end{tabular}

diagnosis of cancer did not affect the length of hospital stay (ETR 1.07, $\mathrm{p}=0.11$ ).

\section{Predictors of extended hospital stay}

Some payers will cover occasional hospitalisations of limited duration (eg, $\leq 5$ days) for hospice patients, for the purposes of respite care or medical attention to a condition which is not the terminal illness. ${ }^{1}{ }^{11}$ Therefore, we used a multivariate logistic regression model to examine the dichotomous outcome of long ( $\geq 6$ days) vs short ( $\leq 5$ days) hospital stays among survivors (table 4 ). We found that patients $\leq 64$ years of age were almost twice as likely to experience a long hospital stay $(\mathrm{OR}=1.89,95 \%$ CI 1.08 to $3.33, \mathrm{p}=0.03)$ compared with those aged 75-84 years. Gender and race/ethnicity did not predict the length of hospital stay. A total of 18 clinical conditions were included in the model; only 3 conditions were significantly associated with a longer length of stay: cancer $(\mathrm{OR}=1.80,95 \%$ CI 1.15 to 2.79 ,
Table 4 Predictors of a long ( $\geq 6$ days) vs short ( $\leq 5$ days) hospital stay among hospice patients who survived to discharge $(n=1457)$ : multivariate logistic regression results

\begin{tabular}{|c|c|}
\hline Patient predictors & OR (95\% Cl) ( $p$ value) \\
\hline \multicolumn{2}{|l|}{ Age, years } \\
\hline$\leq 64$ & 1.89 (1.08 to 3.33$)(0.03)$ \\
\hline $65-74$ & $1.65(0.96$ to 2.85$)(0.07)$ \\
\hline $75-84$ & 1.00 (referent) \\
\hline $85-94$ & 0.91 (0.55 to 1.49$)(0.70)$ \\
\hline $95+$ & $1.16(0.51$ to 2.62$)(0.73)$ \\
\hline \multicolumn{2}{|l|}{ Gender } \\
\hline Male & 1.00 (referent) \\
\hline Female & $1.02(0.71$ to 1.46$)(0.94)$ \\
\hline \multicolumn{2}{|l|}{ Race/ethnicity } \\
\hline White & 1.00 (referent) \\
\hline Hispanic & $1.13(0.72$ to 1.76$)(0.60)$ \\
\hline Black & $1.22(0.65$ to 2.28$)(0.53)$ \\
\hline Other & $1.08(0.31$ to 3.73$)(0.91)$ \\
\hline \multicolumn{2}{|l|}{ Payer } \\
\hline Medicare/Medicaid & 4.87 (2.50 to 9.51$)(<0.0001)$ \\
\hline Private insurance & 1.00 (referent) \\
\hline Tricare/Federal & 2.71 (1.50 to 4.89$)(0.001)$ \\
\hline Other & $0.86(0.42$ to 1.76$)(0.68)$ \\
\hline \multicolumn{2}{|c|}{ Clinical diagnoses* (present vs absent) } \\
\hline Cancer & $1.80(1.15$ to 2.79$)(0.01)$ \\
\hline Heart failure & $1.65(1.00$ to 2.70$)(0.047)$ \\
\hline Stroke & $1.81(1.07$ to 3.07$)(0.027)$ \\
\hline Psychosis & $1.52(0.99$ to 2.34$)(0.059)$ \\
\hline \multicolumn{2}{|l|}{ Discharge destination } \\
\hline Hospice & 1.00 (referent) \\
\hline Healthcare facility & 4.67 (2.94 to 7.41$)(<0.0001)$ \\
\hline Home & 2.61 (1.49 to 4.57$)(0.0008)$ \\
\hline
\end{tabular}

${ }^{*}$ The following diagnoses were also included in the model and all were insignificant: chronic obstructive pulmonary disease, ischaemic heart disease, pneumonia/influenza, HIV, hypertensive disease, non-ischaemic heart disease, any fracture, complication of medical devices, respiratory failure, drug/alcohol dependence, sepsis, acute renal failure, end-stage renal disease and senility.

$\mathrm{p}=0.01)$, heart failure $(\mathrm{OR}=1.65,95 \%$ CI 1.00 to 2.70 , $\mathrm{p}=0.047)$ and stroke $(\mathrm{OR}=1.81,95 \%$ CI 1.07 to 3.07 , $\mathrm{p}=0.027$ ). Patients with psychosis were $52 \%$ more likely to have a long length of stay compared with patients without psychosis, with borderline significance $(\mathrm{OR}=1.52,95 \%$ CI 0.99 to $2.34, \mathrm{p}=0.059)$.

Finally, consistent with the survival analysis results shown in table 3 , the strongest predictors of long versus short stay were payer and discharge destination. Compared with patients insured privately, extended hospital stays were almost five times more likely among those with Medicare or Medicaid $(\mathrm{OR}=4.87,95 \%$ CI 2.50 to $9.51, \mathrm{p}<0.0001$ ), and almost three times more likely among those insured by Tricare $(\mathrm{OR}=2.71,95 \% \mathrm{CI}$ 1.50 to $4.89, \mathrm{p}=0.001$ ). Patients who did not return to hospice were several times more likely to have a long hospital stay compared with those who did return to hospice (discharge to the healthcare facility $\mathrm{OR}=4.67$, $95 \%$ CI 2.94 to $7.41, \mathrm{p}<0.0001$; discharge home $\mathrm{OR}=2.61,95 \%$ CI 1.49 to $4.57, \mathrm{p}=0.0008$ ). 


\section{Financial charges}

The median hospital charge for patients admitted from hospice was $\$ 3916$ (table 5). Reflecting differences in the length of stay, this value varied considerably by discharge status, from $\$ 3424$ for patients who died to \$13 293 for patients who were discharged home. The most frequent charge centre was pharmacy, with $91.6 \%$ of patients having a non-zero charge, followed by room and board $(84.4 \%$ of patients), medical/surgical supplies $(58.9 \%)$, respiratory services and tests $(29.4 \%)$, intensive care unit (ICU, 16.8\%), laboratory (18.7\%), radiology/imaging $(10.0 \%)$ and emergency department $(5.6 \%)$. Low usage levels for laboratory and radiology are consistent with the intent of exclusion of curative-intent treatment for hospice patients. Patients who did not return to hospice were much more likely to have laboratory charges $(57.7-71.0 \%)$ and radiology/ imaging charges (40.3- 44.2\%). ICU usage and charges were highest among patients discharged to a healthcare facility and lowest among patients who died.

In summary, total charges for hospice patients admitted to hospitals in Florida during our 30-month study period exceeded $\$ 25$ million (table 4). Hospice patients who appeared to be exiting hospice care were $10 \%$ $(287 / 2674)$ of patients by number but incurred $32 \%$ (\$8 021 013/\$25 265839 ) of the financial charges due to longer lengths of stay, a greater number of procedures and a greater likelihood of ICU use.

\section{DISCUSSION}

This is one of the largest studies to date of a neglected aspect of the experience of dying patients who chose to enrol in hospice. We capitalised on a new data item added in 2010 to Florida's mandatory hospital discharge reporting system which identified patients who were admitted to the hospital from a hospice programme (either home or facilitybased). Our study revealed that $46 \%$ of patients admitted to the hospital from hospice died before discharge and incurred over $\$ 8$ million in charges. Most of these patients died on the day of admission or within 1-2 days after admission and did not receive life-saving procedures, although $18 \%$ were admitted to the ICU. This suggests that these hospital admissions were medically unnecessary, which is important given that hospitals are not the preferred place of death for many patients. Research carried out on patients' preferences regarding place of death has shown that in an idealised trajectory of hospice care patients want to die at home or in a hospice facility with minimal medical intervention prior to death. ${ }^{12}$ However, for some patients and caregivers, hospital admission in the final hours or days of life may be preferred. For future hospice research, an important patient-centred 'outcome' measure may be whether death occurred in the place and context desired by the patient and family.

A second group of patients admitted to the hospital from hospice care returned to hospice after their stay in the hospital. Many private insurance companies as well as TriCare and Medicare make allowances for 'respite care' hospital stays of up to 5 days' duration in order to give patients' caregivers a short break. Respite care is consistent with the top two admission diagnoses for this group (cancer and palliative care). However, other admission diagnoses (eg, stroke, respiratory failure/ symptoms, sepsis and psychosis) suggest acute illness episodes that home or hospice facility staff were unprepared to cope with. Although there is a substantial body of research on caregiver stress and burnout, this is generally framed as a possible threat to the health of the caregivers themselves rather than a possible reason for hospitalisation from hospice. ${ }^{13-15}$ Additional research on a possible link between the preparedness of home and hospice facility staff and acute illness episodes resulting in hospitalisation is warranted.

Importantly, two groups of hospice patients in our study-those discharged to a healthcare facility and those discharged home-were patients whose admission to the hospital most likely denoted a rejection of hospice care. This hypothesis is consistent with our observations that these two groups were more likely to have a stay longer than 5 days, had higher rates of procedure use, and incurred median financial charges that were much higher than those who died or returned to hospice. Although this was a small group of patients, further study on the phenomenon of terminally ill patients exiting hospice treatment is needed.

\section{Study limitations}

Data about the total number of hospice patients in the state of Florida during our study period were not readily available. Hospice care is not subject to regular surveillance, and the large number of relatively small providers of hospice care makes ascertainment of denominator estimates difficult. On the basis of a recent report from a professional organisation, ${ }^{16}$ we roughly estimate that there 120000 hospice patients annually during our study period in Florida. This would translate to about $1 \%$ of hospice patients being admitted to hospital. However, while hospital discharge data systems have been shown to be reasonably valid sources of patient information ${ }^{17-21}$ and are widely used, ${ }^{22-25}$ we believe this new variable to be significantly under-reported, and that the true number of hospice patients admitted was higher. In particular, patients who are admitted via the emergency department (as opposed to a direct admission by the physician) may be less likely to have their hospice status recorded in the medical record.

A second limitation of our study is that these terminally ill patients suffered from multiple chronic and acute diseases and we did not have access to data which identified the initial reason for referral to hospice. An important empirical question is whether the healthcare trajectories of patients dying from cancer, for example, differ in significant ways from those dying from congestive heart failure or COPD. 
Table 5 Detailed financial charges for patients admitted from hospice by final discharge status, Florida 2010-2012

\begin{tabular}{|c|c|c|c|c|c|}
\hline $\begin{array}{l}\text { Charge centres (listed in } \\
\text { order of decreasing } \\
\text { frequency) }\end{array}$ & $\begin{array}{l}\text { Died before } \\
\text { discharge } \\
(n=1217)\end{array}$ & $\begin{array}{l}\text { Discharged to } \\
\text { hospice }(n=1170)\end{array}$ & $\begin{array}{l}\text { Discharged to a } \\
\text { healthcare facility } \\
(n=149)\end{array}$ & $\begin{array}{l}\text { Discharged } \\
\text { home }(n=138)\end{array}$ & $\begin{array}{l}\text { Total } \\
(n=2764)\end{array}$ \\
\hline \multicolumn{6}{|l|}{$\overline{\text { Total }}$} \\
\hline Per cent with any charge & 100 & 100 & 100 & 100 & 100 \\
\hline Median (\$) & 3424 & 3634 & 11133 & 13293 & 3916 \\
\hline 99th centile (\$) & 46755 & 59606 & 310900 & 252858 & 100431 \\
\hline Total for all patients (\$) & 8041068 & 9203758 & 4074703 & 3946310 & 25265839 \\
\hline \multicolumn{6}{|l|}{ Pharmacy } \\
\hline Per cent with any charge & 86.9 & 95.0 & 98.0 & 97.8 & 91.6 \\
\hline Median (\$) & 434 & 562 & 1949 & 1427 & 586 \\
\hline 99th centile (\$) & 25727 & 17099 & 43220 & 34186 & 24322 \\
\hline \multicolumn{6}{|l|}{ Room and board } \\
\hline Per cent with any charge & 83.0 & 86.3 & 81.9 & 82.6 & 84.4 \\
\hline Median (\$) & 1802 & 1730 & 4290 & 3912 & 2106 \\
\hline 99th centile (\$) & 20400 & 16843 & 31898 & 49462 & 22185 \\
\hline \multicolumn{6}{|l|}{ Medical/surgical supplies } \\
\hline Per cent with any charge & 48.7 & 67.4 & 68.5 & 66.7 & 58.9 \\
\hline Median (\$) & 484 & 484 & 1,167 & 548 & 525 \\
\hline 99th centile (\$) & 9942 & 8476 & 17892 & 193544 & 15048 \\
\hline \multicolumn{6}{|l|}{ Respiratory services/tests } \\
\hline Per cent with any charge & 23.0 & 33.9 & 35.6 & 40.6 & 29.4 \\
\hline Median (\$) & 522 & 585 & 851 & 548 & 571 \\
\hline 99th centile (\$) & 16240 & 7174 & 78726 & 16050 & 16240 \\
\hline \multicolumn{6}{|l|}{ Intensive care unit } \\
\hline Per cent with any charge & 17.9 & 14.4 & 24.8 & 19.6 & 16.8 \\
\hline Median (\$) & 3071 & 2831 & 5542 & 1915 & 2990 \\
\hline 99th centile (\$) & 16276 & 38300 & 62350 & 29505 & 32505 \\
\hline \multicolumn{6}{|l|}{ Laboratory } \\
\hline Per cent with any charge & 6.9 & 19.9 & 57.7 & 71.0 & 18.7 \\
\hline Median (\$) & 506 & 1041 & 3337 & 1915 & 1368 \\
\hline 99th centile (\$) & 62577 & 37357 & 41047 & 35428 & 37357 \\
\hline \multicolumn{6}{|l|}{ Radiology/imaging } \\
\hline Per cent with any charge & 2.7 & 9.7 & 40.3 & 44.2 & 10.0 \\
\hline Median (\$) & 1728 & 1475 & 3135 & 2310 & 2018 \\
\hline 99th centile (\$) & 61895 & 22079 & 61070 & 43598 & 48922 \\
\hline \multicolumn{6}{|l|}{ Emergency department } \\
\hline Per cent with any charge & 1.9 & 4.6 & 24.2 & 26.1 & 5.6 \\
\hline Median (\$) & 1999 & 1886 & 1647 & 1786 & 1851 \\
\hline 99th centile (\$) & 5089 & 6134 & 7189 & 5130 & 6134 \\
\hline
\end{tabular}

A final limitation of this study is the lack of information available about patient and family/caregiver decision-making and preferences in relation to hospice care, hospital admission, ICU admission and use of interventions such as mechanical ventilation and blood transfusions. For the patients who died, it is unknown whether dying in the hospital (often shortly after admission) was in accord with patients' and caregivers' wishes, or represented last-minute failures of hospice care to shield patients from unwarranted medical intervention.

\section{Conclusions and future directions}

Our results and those of previous studies ${ }^{2-9}$ raise difficult and significant questions about the ethics and pragmatics of end-of-life medical care and the intentions and scope of hospice care. Commonly used templates for patient advance directive documents, for example, 5 Wishes, ${ }^{26}$ include lists of 'life-support treatment' that patients may want to avoid, such as cardiopulmonary resuscitation, mechanical ventilation, tube feeding, major surgery, blood transfusions, dialysis and antibiotics. In our study, the use of procedures was very low, except among patients who survived and did not return to hospice. In a report on hospice patients with hip fracture, ${ }^{7} 83 \%$ received hip surgery and consequently had improved survival compared with those who did not undergo surgery. Patients dying of a terminal disease (eg, cancer) may experience painful and/or life-threatening acute illness events that are completely unrelated in pathology (eg, stroke or hip fracture), and which were not directly addressed in advance directives or hospice care plans. Patients, caregivers and healthcare providers may all find themselves uncertain about the most ethical and compassionate course of action in these situations. 
We would advocate inclusion of a simple hospice indicator in additional clinical registries and hospital reporting systems, as this would be a low-cost means of creating additional data resources for exploring hospice patient healthcare trajectories. Future studies should investigate variations in hospice patient healthcare trajectories by cause of terminal illness, as well as incorporate patient and caregiver needs and preferences. An ideal study design would prospectively link subjective patient-centred data (eg, advance directive content, do not resuscitate, patient-reported values and preferences) and objective healthcare encounter data (eg, emergency room visits, inpatient stays and outpatient care).

Contributors EBP conceived and designed the study. EBP and SW analysed the data. SW, BD and EBP contributed substantially to interpretation of the data, drafting and revision of the article for important intellectual content and final approval of the version to be published.

Funding This study was supported by a USA Department of the Army grant \#W81 XWH 09-2-0175 (BD).

Competing interests None.

Provenance and peer review Not commissioned; externally peer reviewed.

Data sharing statement No additional data are available.

Open Access This is an Open Access article distributed in accordance with the Creative Commons Attribution Non Commercial (CC BY-NC 4.0) license, which permits others to distribute, remix, adapt, build upon this work noncommercially, and license their derivative works on different terms, provided the original work is properly cited and the use is non-commercial. See: http:// creativecommons.org/licenses/by-nc/4.0/

\section{REFERENCES}

1. Hospice Facilities Manual. Florida Blue Insurance; August 2012. http:// providermanual.bcbsfl.com/ARS/cr/bg/Pages/Hospice-Facilities .aspx

2. Meng H, Dobbs D, Wang S, et al. Hospice use and public expenditures at the end of life in assisted living residents in a Florida Medicaid waiver program. J Am Geriatr Soc 2013;61:1777-81.

3. Tan ST, Jatoi A. End-of-life hospital costs in cancer patients: do advance directive or routes of hospital admission make a difference? Oncology 2011;80:118-22.

4. Weckmann M, Freund K, Bay C, et al. Medical manuscripts impact of hospice enrollment on cost and length of stay of a terminal admission. Am J Hosp Palliat Care 2013;30:576-8.

5. Teno J, Gozalo P, Casarett D, et al. Does hospice improve quality of care for persons dying from dementia? J Am Geriatr Soc 2011;59:1531-6.

6. Munn J, Hanson L, Zimmerman S, et al. Is hospice associated with improved end-of-life care in nursing homes and assisted living facilities? J Am Geriatr Soc 2006;54:490-5.

7. Leland N, Teno J, Gozalo P, et al. Decision making and outcomes of a hospice patient hospitalized with a hip fracture. J Pain Symptom Manage 2012;44:458-65.
8. Olsen M, Bartlett A, Moynihan T. Characterizing care of hospice patients in the hospital setting. J Palliat Med 2011;14:185-9.

9. Wallace $\mathrm{E}$, Cooney $\mathrm{M}$, Walsh $\mathrm{J}$, et al. Why do palliative care patients present to the emergency department? Avoidable or unavoidable? Am J Hosp Palliat Med 2013;30:253-6.

10. Carroll KJ. On the use and utility of the Weibull model in the analysis of survival data. Control Clin Trials 2003;24:682-701.

11. Medicare Hospice Benefits. Baltimore, MD: Centers for Medicare \& Medicaid Services, 2013. http://www.medicare.gov/Pubs/ pdf/02154.pdf

12. Fischer S, Min SJ, Cervantes L, et al. Where do you want to spend your last days of life? Low concordance between preferred and actual site of deal among hospitalized adults. J Hosp Med 2013;8:178-83.

13. Gitlin L, Rose K. Factors associated with caregiver readiness to use nonpharmacologic strategies to manage dementia-related behavior symptoms. Int J Geriatr Psychiatry 2014;29:93-102.

14. Otis-Green $\mathrm{S}$, Juarez $\mathrm{G}$. Enhancing the social well-being of family caregivers. Semin Oncol Nurs 2012;28:246-55.

15. Choi J, Tate $\mathrm{K}$, Sherwood $\mathrm{P}$, et al. Fatigue in family caregivers of adult intensive care unit survivors. J Pain and Symp Manage 2014 pii: S0885-3924(13)00666-0. Published Online First: 16 Jan 2014. doi: 10.1016/j.jpainsymman.2013.09.018

16. Florida Agency for Health Care Administration. Florida need projections for hospice programs: Background information for use in conjunction with the October 2013 batching cycle for the January 2015 Hospice Planning Horizon. http://ahca.myflorida.com/MCHQ/ CON FA/Publications/docs/FINeedProjections/October2013 HospiceNeedProjections.pdf. Published 27 Sept 2013 (accessed 27 Jan 2014).

17. Quan $\mathrm{H}$, Eastwood C, Cunningham CT, et al.; IMECCHI investigators. Validity of $A H R Q$ patient safety indicators derived from ICD-10 hospital discharge abstract data (chart review study). BMJ Open 2013;3:e003716.

18. Saczynski JS, Andrade SE, Harrold LR, et al. A systematic review of validated methods for identifying heart failure using administrative data. Pharmacoepidemiol Drug Saf 2012;1:129-40.

19. Kirkman MA, Mahattanakul W, Gregson BA, et al. The accuracy of hospital discharge coding for hemorrhagic stroke. Acta Neurol Belg 2009;109:114-19.

20. Quan H, Parsons GA, Ghali WA. Validity of procedure codes in International Classification of Diseases, 9th revision, clinical modification administrative data. Med Care 2004;42:801-9.

21. De Bruin ML, van Hemel NM, Leufkens HG, et al. Hospital discharge diagnoses of ventricular arrhythmias and cardiac arrest were useful for epidemiologic research. Clin Epidemiol 2005;58:1325-9.

22. Mark TL, Lawrence W, Coffey RM, et al. The value of linking hospita discharge and mortality data for comparative effectiveness research. J Comp Eff Res 2013;2:175-84.

23. Lin G, Ma J, Zhang L, et al. Linking cancer registry and hospital discharge data for treatment surveillance. Health Informatics $J$ 2013;19:127-36.

24. Taylor JA, Pandian RS, Mao L, et al. Using inpatient hospital discharge data to monitor patient safety events. J Healthc Risk Manag 2013;32:26-33.

25. White $\mathrm{RH}$, Geraghty $\mathrm{EM}$, Brunson $\mathrm{A}$, et al. High variation between hospitals in vena cava filter use for venous thromboembolism. JAMA Intern Med 2013;173:506-12.

26. Towey J, Aging with Dignity. Five Wishes. 2011. http://www. agingwithdignity.org/forms/5wishes.pdf 